$\underline{\underline{\beta}}=$

\title{
Congenital abnormalities: Experiences of parents at Oshakati Intermediate Hospital, Oshana region, Namibia
}

\author{
Marian Sankombo ${ }^{1}$, Linda N Nghipondoka- Lukolo ${ }^{2 *}$, Charles Lukanga Kimera ${ }^{3}$ \\ ${ }^{I}$ Ministry of Health and Social Services, Namibia \\ ${ }^{2}$ School of Medicine, Faculty of Health Science, University of Namibia, Windhoek, Namibia \\ ${ }^{3}$ School of Medicine, Faculty of Health Science, University of Namibia, Windhoek, Namibia \\ *Corresponding author E-mail: Inlukolo@unam.na
}

\begin{abstract}
Background: Congenital abnormality (CA) is one among eminent problems in the society that affects the livelihood of the individual, communities and the health sector. It creates uncertainty among family members as they strive to identify ways and means to assist one another in the upbringing of these children born with an anomaly. The ultimate purpose of this study was to describe and explore the experiences of parents of children with congenital abnormalities and to identify the source of support such as parents employs when dealing with the child born with congenital abnormalities. This study was conducted at Intermediate Hospital Oshakati (IHO) in Namibia's Oshana region.

Methods: A qualitative, explorative and a contextual study design using a phenomenological approach was utilized throughout this study. In-depth interviews were conducted with twelve "purposefully" selected participants from the population of parents of children born with congenital abnormalities whose children were either admitted in hospital or brought for follow-up. Data analysis was done using a content analytical method.

Results: Data were derived from 12 participants interviewed, comprised of parents of children with reversible and irreversible conditions, long hospitalization, more frequent follow ups and those waiting for surgery. The results were categorized in seven categories, including: 1) A child with congenital abnormalities: the impact of disability; 2) Family relationships; 3) Parenting expectations and practices; 4) Altering one's family daily life- treading a new path; 5) Social support; 6) Formal services; 7) Societal and community acceptance.

Conclusion: The expectations parents had for a normal child becomes a nightmare when the child they were expecting is born with the disability. Living with such a child can be stressful for parents and other family members. Therefore, exploring and describing the lived experiences of parents of children born with congenital abnormalities is an important in the process of finding ways to assist or support parents to provide proper care for their children.
\end{abstract}

Keywords: Parents; Experiences; Children; Congenital Abnormalities.

\section{Introduction}

Congenital abnormalities are numerous and ranges from physical and mental abnormalities, the severity of which usually determine which individuals will survive. Some congenital abnormalities are incompatible with life and so individual suffering from these are never seen in the general population. Approximately 3 percent of infants have a major structural malformation that is detectable at birth. By age 5, another 3 percent have been diagnosed with a malformation, and another 8 to 10 percent is discovered to have one or more functional or developmental abnormalities by age 18 . For most birth defects - approximately 65 percent, the etiology is unknown (Schardein, 2000). Importantly, chemically induced birth defects, which include those caused by medications, are believed to account for less than 1 percent of all birth defects (Center for Drug Evaluation and Research, 2005). How these abnormalities are perceived to differ from region to region possibly depending on the socioeconomic status of the family, the assistance from the community and the governments? Having a child with congenital abnormality is shocking and emotionally traumatizing to a mother. These feelings are a reflection of a battle within the parent in grasping and accepting the difference between expectations and the real disabled child. Some of those with abnormalities may be lucky and get formal education if the parents are economically capable but there may be a lot of dischronation when it comes to finding jobs to leave alone getting access to offices where the prospective jobs can be gotten.

\section{Methods}

\subsection{Study design}

This is a qualitative, phenomenological, explorative and contextual design in nature. The researchers employed explorative research design to examine the life experiences of parents of children with congenital abnormalities upon receiving news about the condition of their children.

\subsection{Participants}

The study includes all parents of children below the age of 14 years born with congenital abnormalities who either were admitted in IHO or visited the hospital on a monthly or quarterly basis for reasons pertaining to the conditions of their children. 


\subsection{Sampling}

The population for this study consisted of Oshiwambo speaking mothers who were admitted to the hospital. The cohort register was also used in this regard to identify some of the study participants who were purposefully selected according to the type of congenital abnormality. The sample consisted of (12) twelve participants (identified as CA1 to CA12), their age range was 17 to 45 years with a mean age group of 33 years.

\subsection{Study setting}

The study was conducted at Intermediate Hospital Oshakati (IHO) in Oshana region of Namibia. Five hospital disciplines participated in the study, namely: Physiotherapy department, Occupational Therapy, Orthopedic department as well as both Medical and Pediatric Surgical units.

\subsection{Piloting}

We conducted a pilot study mainly to test the feasibility of the proposed study. All amendments and changes were done before the actual study.

\subsection{Data collection}

The researchers conducted personally in-depth interviews with the twelve parents of children with congenital abnormalities. It was conducted in the language of their choice, which was Oshiwambo. Probing was used to explore more in-depth information. Furthermore, the interviews were recorded, and field notes were taken with the participant's permission, to assist the researchers not to miss any valuable information about the study. The central question asked was:

"What are your experiences in raising a child with congenital abnormalities?"

\subsection{Ethical considerations}

Permission to conduct the research was sought from the hospital management, and informed consent's obtained from participants. Fundamental ethical principles based on a human right were respected throughout the study; such as: rights to self determination, privacy, anonymity, confidentiality, fair treatment and protection from harm.

\subsection{Data analysis}

Content analysis was used to organize data into categories in order to synthesize valuable and meaningful information. Furthermore, the results obtained from all the participants were consolidated, thus giving a clear understanding on experiences of parents of children with congenital abnormality at the Intermediate Hospital Oshakati (IHO).

\subsection{Measures to ensure trustworthiness of information}

The researcher maintained the true value, applicability, neutrality, validity and reliability in the whole research process, by addressing the following:

Dependability: An external inquiries audit, dense description of the research methods, stepwise replication, triangulation, peer examination and code-record procedure. To ensure validity and reliability the manuscript was given to experts for proof reading. Credibility: This was maintained through prolonged engagement, persistent observation, triangulation, and peer group debriefing and member checks.

Confirm ability: The researchers safely kept the recorded tape and written documentation from the interview to determine whether the conclusion and interpretation can be traced to their sources, and if they are supported by the inquiries (Brink, 2007).
Transferability: through thick descriptive, clear criteria in nominating the sample as well as time sampling, clear description of the participants.

\subsection{Demographic data of participants}

A total of 12 participants were identified. They were mothers of children with congenital abnormalities, ranging from cerebral palsy, Down syndrome, cleft palate and hydrocephalus. On average the participants had one child with congenital abnormality except one participant with two. The highest level of education attained ranged from grade 7 to grade 12 with grade 9 being the average highest educational grade achieved. Three of the participants were employed; seven were unemployed and two had small businesses, whilst four of the participants were married, seven were single mothers and one was a widow.

\section{Results and discussions}

The research sought to identify the commonalities and variations in families' experiences. Seven categories of description reflecting key variations of meaning emerged from the analysis. The commonalities and variations in mothers' descriptions are illustrated with quotes from the transcripts. The quotes provide illustrative examples of the category that supplement the excerpts' description. There were no sub-categories that emanated from the emerged categories. This was because of the nature of information gathered. The seven categories derived from mothers 'experiences are illustrated in the table below:

Table 1: Categories

\begin{tabular}{ll}
\hline NUMBER & CATEGORIES \\
\hline Category 1 & The impact of disability \\
Category 2 & Family relationships \\
Category 3 & Parenting expectations and practices \\
Category 4 & Altering one's family daily life- treading a new path \\
Category 5 & Social support \\
Category 6 & Formal services \\
Category 7 & Societal and community acceptance \\
\hline
\end{tabular}

\subsection{The impact of disability}

This core category describes the initial impact on the birth of a child with congenital abnormality on the mother. The circumstance under which this news is received is clearly recalled by the mothers because this is a significant event that is maintained as part of the on-going family narrative.

The impact of this experience is evaluated and re-evaluated over time as mothers consider the changes that the event has brought into their lives. Variations in reaction and its impact were observed in the excerpts that follow:

A 36-year-old mother whose child has a cleft lip, and palate said: "I was shocked; I became sick and I developed high blood pressure. I started thinking a lot of things asking myself, what I did wrong to my God, what did I do to deserve this?"

A mother whose child is hydrocephalus said:

"I was worried; I was worried (repeating herself), and I started asking myself why, what has caused this problem. What have I done my Lord??"

Another mother whose child is hydrocephalus had this to say:

"I first did not believe what they told me because the child's head was just normal at birth, I did not expect to be like that (Referring to the big head now); I am not sure how I felt!!!" (She becomes emotional).

In this category, the emphasis was mainly on the parental reaction and impact of such a reaction upon learning about their child's disabilities. Kathy \& Mike (2001) referred to the birth to the baby as a major event in the life cycle of the family and a source of great expectations, so giving birth to a baby who manifests with a different appearance or who presents with life-threatening conditions triggers a series of reactions. 
The feeling of guilt and denial by CA2 and CA3 was also reported by Reichman, Corman \& Noonan (2008) that stress may be associated with guilt, blame, or reduced self-esteem and may divert attention from other aspects of family functioning.

The situation was slightly different with CA6 a 42 -year-old mother whose child is a down syndrome and congenital heart disease. She had this to say:

"When the doctor told me that my child had Down syndrome and heart problem, I accepted it because I could also see that the child does not look like others, I accepted the condition it is God's creation"

Whereas CA7 a 45 year old mother whose child has Down syndrome did not say anything when the news was given to her by the doctor, her response shows a crushed and despaired heart as stated below:

"I did not say anything or do anything, the doctor told me first that your child was Down syndrome, and we are going to refer you to the rehabilitation centre, then I just said its ok it is fine so long I am having my son"

At times responses like this show a personality trapped between hope and despair and this is reflected in her subsequent response to the question. How do you feel deep inside you about the condition of your child:

Oh!!!! (Takes a deep sigh) I always feel bad, and sometimes I always cry because of my son

Some of the mothers had the same experience when they discovered that their children had a congenital abnormality, they felt bad, angry and abandoned by their God, or as if they were the cause of their children's' disability. Some of them always ask themselves and their God, why them. Some of them still feel bitter in their hearts and physically cry when they reflect on and see their children with the abnormalities. Having a child with congenital abnormality is shocking and emotionally traumatizing to a mother as revealed by some of these mothers. These feelings are a reflection of a battle within the parent in grasping and accepting the difference between expectations and the really disabled child. Matthew, Modrcin \&Robinson (1991) reinforces this experience, and they state that the initial diagnosis of a child's disability confronts the family with the discrepancy between their hopes for the child and the child's actual abilities. This discrepancy between their child's developmental capabilities and the child's peers increases a sense of being isolated from other families.

Mothers describe the feelings and emotions they experienced with the disabled child's birth with great suffering and grief. An abrupt disturbance strikes their emotional balance. They live a unique and non-transferable experience, permeated by crying, loneliness, helplessness and a great anxiety to escape this situation. Therefore, the mother lives a great emotional and existential conflict, feeling abandoned and powerless to continue living. She wishes to give up the struggle, which, at that moment, feels too painful. She shows herself vulnerable in the face of the situation, not being able to comprehend the reality of having a disabled child. The mother feels unhappy, showing feelings of disbelief and hopelessness.

The category illustrates the initial and ongoing effect that the birth of the child with congenital abnormality had with the mother, as well as the significant impact of the event on other family members. Sajjad (2010), acknowledges that when parents are told about having a child with disability, they generally progress through six emotional stages: disbelief, guilt, rejection, shame, denial and a feeling of helplessness. This observation concurs with the findings of this current study, as reflected by responses given above.

An unpredictable, hard-to-manage health condition can contribute to anxiety, conflict, and depression in a family, drain financial resources, and leave the children without adequate parental care. In addition, a progressive, terminal condition can bring feelings of grief, powerlessness, and loss of structure to the family environment.

\subsection{Family relationships}

This category identifies how the child's condition is affecting the cohesion of the immediate and extended family. It includes individuals' relationships with the congenitally abnormal child, but also the nature of the relationships between family members that do not include the child but which are affected by the presence of the child. It also reflects the degree of acceptance of the child by family members.

Some of the parents described their family relationships as normal and supportive as highlighted by a few extracts from the interviews below:

A 42 year mother of a child with cerebral palsy had this to say about family relationships:

"My family and husband's family are fine with the child, like now the child is with my mother-in-law and I know she was treated the child well, immm!!!! The problem is that she is too old. I once decided to take the child to Windhoek, but I thought again that the child was still small to be sent to Windhoek."

Responding to the question, what was the father's reaction when he saw the child for the first time? One mother had this to say:

"Like the other people were saying, he encouraged me to take the child to the church and hospital. He felt pain, but he accepted the condition of the child"

A 42 year mother of a 7 year old child with Down syndrome expressed gratitude to the relationship she had with her family as highlighted by the following extracts from her interview:

"I did not observe any change from both my husband's and my family. The only thing I observed is that they felt sorry for the child, because every time the child had to be taken to and from Windhoek, until the child was finally referred to South Africa for farther treatment."

Asked about the reaction and relationship she has had with her husband, the mother has had this to say:

"No change. The relationship remained the same. He also accepted the child because he could see that the child does not look like other children."

All the above participants highlighted the importance of support from their partners and family members. The in-laws were very supportive as well as the mother's family. Extended family members such as aunts and cousins had good relationships with all the four participants. This is confirmed by Rosenweig \& Huffutter (2003) who asserted that families with children born with CA tend to function more successfully with an effective family support system because these are people available at all times and may render assistance any time the need arose.

However, two of the participating mothers had mixed relationships with their families, that is, some family members accepted their congenitally abnormal children, while others did not accept them.

A 32 year old mother of a child with hydrocephalus had this to say pertaining family relationships:

"My husband also told me that the child would be operated, he used to call to find out the condition of his child"

Some of the participants had really nasty and emotionally traumatizing family relationships, which compounded the burden of looking after the congenitally disabled child. Some of these mothers were emotionally drained and were crying throughout the interviews, especially when the question of acceptance of the child by family members was posed. What follows below are some of these experiences that the participants went through.

A 33-year-old mother of a congenitally disabled child had good relationship with her husband, but she and her husband were so much traumatized by the husband's relatives as she narrated below:

"My husband is depressed because his family did not accept the child up to now. They used to tell him bad words like he is stupid. $\mathrm{He}$ is having a disabled child. One time this year (2013) in May, he was on leave at home and one of his uncles (grandfather) asked him to take him to the cattle post, and he responded that he is busy because he is taking Peter (the child) to the hospital for measure- 
ment of the wheelchair. The uncle said for what purpose if the person is disabled, what is it going to help, for what reason. So he is always depressed."

Sajjad, (2010), concludes in his study on the impact of disability that anger, sense of loneliness and depression faced by mothers of children with intellectual disability has a negative impact of their family life. Reichman, et al. (2008), acknowledges that living with a disabled child can have profound effects on the entire family parents, siblings, and extended family members. The authors further state that it is a unique shared experience for families and can affect all aspects of family functioning. On the positive side, it can broaden horizons, increase family members' awareness of their inner strength, enhance family cohesion and encourage connections to community groups or religious institutions.

Family conflicts emerge as a source of concern for the mother which is experienced due to the difficulty in perceiving the child as having certain capabilities and in accepting its disability. As she goes through this intense suffering, the mother feels lonely and distanced from the real situation and from her family members. This distancing and loneliness make it difficult for her to become involved in the situation and consequently, impaired her understanding or attribution of the meaning of her existence.

The above findings coincide with the writings of Albrecht (1995) who stated that a supportive relationship is an important part of keeping us healthy and may reduce the chances of developing poor physical and mental health. In addition to that Uchino, Cacioppo \& Kiecolt- Glaser (1996) revealed that having a strong network of friends and family who provide social support is lined to good health.

\subsection{Parenting expectations and practices}

This category represents how mothers perceived their parenting role in relation to their child and the practices in which they engaged to support their child's learning and development. Based on this notion, some mothers acknowledged the need for a special school to cater for their children's needs as the current school scope of practice within the region is limited to blind and deaf children. The following quote is an evidence:

"We want the government to help us with paying fees for kindergarten for the disabled children and we want a special school for our disabled children. They must also attend to the foot of the child so that he must be able to walk". maybe to increase the fund to N\$500 “

(Father interjects) "No, it's not enough because the kindergarten only is costing N\$600 per month, so N\$200 is not enough".

Another mother had this to say: "... They must give me money to buy milk for the child, even to repair the abnormality."

Most mothers experienced increased costs of caring for the child with congenital abnormalities and these costs were related to buying disposable nappies, milk and transport to the hospital for monthly follow ups.

Canam (2011) concurs with these financial woes that confront parents with disabled children, and the authors further stress that parents of children without special needs requires additional resources and support from outside the family to manage the ongoing care about their children and family life. This support includes appropriate medical, educational and rehabilitative services for the child, information, respite care, and emotional support from friends and groups outside the family. Parents may have support in one area and not enough in another. For example, parents may have a lot of friends who provide emotional support, but they may not have anyone who can look after their child so that they can get a weekend of respite. It is important for parents to recognize the strengths and limitations of their support network and develops new resources to address the gaps. Parents need to be reminded that doing their best does not mean doing everything themselves.

\subsection{Altering one's family daily life- treading a new path}

This category exposes the push and shifts that the family undergoes as they reposition themselves to better the care and understanding of the congenitally abnormal child. Suddenly the mother finds herself in a position where she has to adjust the family daily life and enter a new path, sometimes in a different direction and at times within the same direction.

The family's ways are transformed with the child's disability, initially showing vulnerability to everyday activities and in other moments, re-organizing themselves and showing a disposition based on what is to come.

A mother who has a child with cleft lip and palate cannot breastfeed normally, instead she has to express her milk first then feed the baby. This may appear to be a small change, but this has an emotional strain upon the mother, as breastfeeding is regarded as the pillar of motherhood, failure of which a mother disqualifies herself. CA2 had this to say:

"....It is difficult I experienced difficulties with the feeding of the child, so I have to express milk from the breast and feed the child" What else?

CA3 has a hydrocephalus child and has 6 other normal children, and her lifestyle changed with the birth of the congenitally abnormal child. She has to go to the hospital every month and because of the size of the children' head, she admits it is difficult to carry the child.

"....It is difficult to carry the child".

"....Many times, every month for five months"

"......... feel very bad about it."

CA9 had to change her life style now that she is expected to be at the hospital often and she stays very far from the hospital and had this to say:

"It is very difficult since I am staying at Okalongo, and it is very far from here. I always struggle with transport money because sometimes the father of the child is not around to give me transport money since most of the time he travels"

Some of these congenital abnormalities require prolonged hospitalization, and this completely alters daily routine of the mothers. Some of these congenitally disabled children need special care yet most of the time the mother is the only available person competent to execute care.

Heiman (2002) had similar findings, some of the parents interviewed for his study reported, the challenge of carrying the child everywhere as seen in this extract from his study: "I can never leave him alone"; "I have to take her with me everywhere I go." Most of the parents spoke about the various difficulties. They themselves have to cope with, while others mentioned neverending emotional and/or physical fatigue, social isolation, and the feeling of lack of freedom.

The findings of this current study are similar to what was found by Cousino \& Hazen (2013) when they explored the factors in the child care that contributed most to the added strain. Their findings revealed that the demands for caring created greater stress than the severity of the disability.

Daily life and activities of all parents in this study were affected by the presence of a disabled child. Much time was spent looking after the child and as a result, they were not able to do other important activities such as business and caring role of other siblings.

\subsection{Social support}

Social support is important for health and stress relief; it increases resilience, multiplies joy, and softens sorrow (Scott, 2007).An An important resource for coping with stress is the presence of others in whom one can confide and from whom one can expect help and concern. Mothers interviewed during this study confirm the findings of Burton, et al. (2009) and relates how social support systems such as religion, peers and formal services available in their community have assisted them to accept their children as illustrated by the following extract from one of the mothers:

Some comments illustrate this category: 
"The words from the pastor and my husband assisted me to accept the situation because after that I did not even consider what my mother-in-law was accusing me of doing. After birth it was hard to accept, but the hospital pastor came and advised me to pray every day, because at least I gave birth to a live child, I should thank God for that and accept what God has given me, so I accepted. Then by that time I was relieved from worries. The other thing when my husband told me about one of his family members with the same condition and after seeing this cousin to my husband, I became much better and I accepted my child."

Pastors play a crucial role in building self-belief among their members who have social problems, by proclaiming divine help from the almighty. They will then start to accept their situation, especially when they know they are not alone in the battle, but God is with them. God becomes the shoulder to cry on and replaces the emotional void in their hearts, and suddenly they have someone to talk to, who has all the time at the world to listen to them. So when things are not fine, when the stress levels are high, they turn to their God, and they cast all their burdens and sorrows unto Him, and they feel much relieved. This, in the long run, gives them the strength and will power to a soldier on.

At times, the social support fabric can be torn by other members of the fabric who are not supportive. Usually, social recovery is a function of health worker impact and the strength of the positive support network as highlighted by participants:

"Hopes that the child's lips will be fixed keeps me strong. People who feel sorry for the baby make me feel bad. The assurance from my mother and health workers about the possibility to restore my child's image (lips and palate) assisted me to cope and accept the condition. The other thing is my sister who is having the same condition like my child"

A social support system may include meeting other mothers going through the same condition and this encourages mothers with congenitally abnormal children as expressed by CA8:

"What gives me, courage is that whenever I bring my child to the hospital, I will see that we are many parents who are having disabled children and when we are here we normally share ideas on how to take care of our children"

Considering that other mothers are experiencing a similar situation, or maybe worse, and comparing herself to them, the mother launches herself into living and doing things for the disabled child. She perceives herself as having to adopt the characteristics of the perfect, ideal mother and for that, she acts towards accepting all the requirements of the outside world, coping with the situations she experiences with resignation.

\subsection{Formal services}

This category represents the mothers' experiences with health care services primarily. Most of the interviewed mothers were furious about healthcare workers' failure to disclose the condition of their children as well as failure to give as much information about the condition as reported by one participant:

"At the beginning if the nurses see that you have given birth to a baby with congenital abnormalities, aren't they used to ask and show the sex of the baby immediately, but now since they keep the child away from you for a while after birth, when they bring the baby, they don't even tell you anything about the abnormality of the baby, the nurse just gives you the baby and off, she goes, without even telling you or counsel you. At least once they bring the baby they must be able to tell you that the baby is having such a problem or when they are showing you the sex of the baby, they must also inform you about the abnormalities of the baby and how you should handle it. Not just to give you the child without saying anything. Like with my baby, I just saw the defect myself and it was only after the baby started crying when I saw that even this was open (holding the palate).). That is what bothered me because I knew only of the defect in the lip, but when the child cried I saw the big opening inside. They should tell us in advance so that when they are bringing the baby to you, you already know that the child is like this" (speaking in a crying voice).
The earlier, the mother knows about the disability of her child the better she will be prepared to cope with the disability. If the mother is psychologically prepared and has accepted the condition of her child, then she will be prepared to seek more information. Failure to disclose and explain the condition of the child to the mother has negative implications of the treatment plan of the child.

According to Matthew, et al. (1991), practitioners must be willing to discuss openly with families what is known about their child's physical handicap. Parents need this information in order to make sense of what is happening with their children and to enhance their ability to cope with this situation. In their study, Barlow, Harrison \& Shaw (1998) revealed that lack of opportunity to discuss the condition of the child and delay in obtaining treatment may result in high-stress levels in parents of children with CA.

Though most mothers interviewed were furious about the health care workers, some felt health care workers helped them so much, as eluded by CA5:

"They are assisting me because they always come and ask me about the child's condition, and if they find a problem they inform the doctor. They are assisting us much because even at night they could come and ask you the condition of your"

Another participant agreed that health care workers help them a lot:

"They help the children with their exercise; they take their weight, to see if they are malnourished. They take their height to see whether the child is still growing, they check x-ray to see if the muscles are still working properly and also the stomach. They are teaching us how to massage the child. They are also encouraging us to play with the child and make the child laugh."

Although the mother searches for sources of support from health care professionals to face this moment and to be able to take care of her child with more safety, she does not find any. For the mother, not receiving the necessary information regarding the child's disability means not being seen and respected as a person and as a human being, not being respected in her feelings. This in turn leads to experiencing feelings of disbelief and hopelessness. The mother looks like some kind of explanation for why this happened to her, worrying about the exact cause of the disability. This fact is frustrating, since it is not always possible to determine the reason for the child's disability.

\subsection{Societal and community acceptance}

Participants face the impact and the rejection from people regarding the child's disability and suffer the curiosity manifested by the looks, comments and attitudes in the presence of their children in the different environments they visit. One of the mothers was not comfortable to walk around with her child because of the people staring at them, but with counselling she became comfortable, below is the supporting quote:

"The people were shocked and scared when they first saw the child since such conditions are not very common in their community. Yes, when you are among them, everyone will be looking after the child, most of the time they do not talk to you or greet you. However, my husband told me while I was still in the hospital not to worry, because his cousin was also born with such as defect"

Another participant had this to say:

"They also accepted the child, but not fully. When I am with the child people used to ask me a lot of questions like why are you not sending the child to your grandmother? Isn't she alive? I used to respond that I will stay with my child. Sometimes you will hear someone say you people with your disabilities then you feel very bad about it and think that you need to stay with your own child. Sometimes I used to go to the village to visit my grandfather, because whenever I go there, I would bring food, but when it is time in the hospital follow up. I have to come back and take my child to the hospital. No one wants to help me to take the child to follow up". 
The primary need of all human beings is to be loved and accepted by others, and nothing is more painful than watching your child being isolated and rejected by people around you. The community's attitudes and practices have a bearing on the emotional engagement and recovery of the mother with a congenitally abnormal child, and effective community support framework helps the mother to cope with her child's condition (Lavoie, 2014).

The findings of the current study revealed how crucial community/ societal support has been in moulding the coping mechanism and reducing stress levels of parents of disabled children. The above findings are in conformity with what was found during the study done in Pakistan, where lack of social interaction with their children with society was among the primary causes of stress in parents of disabled children (Sajjad, 2010).

In many countries, responses in the situation of children with disabilities are largely limited to institutionalization, abandonment or neglect (UNICEF 2013). These responses are the problem and are rooted in negative or paternalistic assumptions of incapacity, dependency and difference that are perpetuated by ignorance. What is needed is a commitment to these children's rights and their futures, giving priority to the most disadvantaged as a matter of equity and for the benefit of all. Children with disabilities encounter different forms of exclusion and are affected by them to varying degrees depending on the type of disability, they have, where they live and the culture or class to which they belong(UNICEF 2013)

\section{Limitations}

The researchers experienced difficulties in locating study participants as at the time of data collection, follow up dates of most of the participants already passed on. Therefore, researchers had to use a cohort register to trace those parents. Some participants who were reachable telephonically, reported to have moved to other places, so the time frame for data collection had to be extended to allow those parents who could not be accessed on the follow-up dates to take part in the study.

\section{Contributions}

This study is an original contribution to knowledge on the experiences of mothers of children with congenital abnormality in the Intermediate Hospital Oshakati, in Namibia. The categories that were identified derived from the findings after analysis and interpretation of the results supported the aim at the study.

\section{Conclusions}

In this paper, categories identified were presented and discussed. It included psychological and emotional challenges of being stressed by caring tasks and having worries about the present and future life of their children. The study also found that parents had feelings of sadness, and inner pain or bitterness due to the expectations they had for a normal child. They were terrified and traumatized by the reactions of some spouses/family members and community who failed to comprehend the child's condition. Social challenges included inadequate social services for their children, such as special schools, specialized health care services, stigma, the burden of caring tasks, lack of public awareness on congenital abnormalities and lack of social support. Economic challenges included poverty, child care interfering with various incomegenerating activities in the family, and other extra expenses associated with the child's condition.

\section{Acknowledgement}

We would like to thank the Ministry of Health and social services to for granting us permission to contact this research in the Osha- kati Intermediate Hospital and sincere gratitude to all participants who voluntarily participated in this study.

\section{References}

[1] Albrecht, D.G. (1995). Raising a child who has a physical disability. New York: John Wiley \&Sons, Inc.

[2] Barlow, J.H., Harrison, K. \&Shaw, K. (2004). The experience of parents in Juvenile arthritis: Clinical child Psychology \& Psychiatry Volume 3, Issue no. (3), pp 447

[3] Braeneuner, S. \& Media, D. (2014). What Causes Increased Stress for Parents of Children With Special Needs: Nashville.

[4] Brink, H., Van der Walt, C. \& Van Rensburg, G. (2006).Fundamentals of Research Methodology for Health Professional. Cape Town: Juta.

[5] Burton,L., Westen, D.,\& Kowalski,R. (2009). Psychology 2nd Australian \& New Zealand Edition.Australai: John Wiley \& Sons.

[6] Canam, C. (2011). Maintaining Family Life: Meeting the Challenge of Parenting Children withChronic Health ConditionsBC Council for Families.

[7] Cousino, M.K. \& Hazen, R.A. (2013). Parenting Stress among Caregivers of Children With Chronic Illness: A Systematic Review. Journal of Pediatric Volume 38 No. 8 Page 809.

[8] Heiman, T. (2002). Parents of Children with Congenital Abnormalities: Resilience Coping and Future Expectations. Journal of Development and Physical Disabilities. Vol.14, Issue No. 2. https://doi.org/10.1023/A:1015219514621.

[9] Kathy, C. \& Mike, F. (2001).The Stigma of Social Exclusion in Health Care. London and New York: Routiledge.

[10] Lavoie, R. (2014). Helping Children With Learning Disability Find Social Success.

[11] Matthew, J., Modrcin,M.S.W. \& Robison, J.M.A. (1991). Clinical Care Update: Children andFamilies.Parents of Children with Emotional Disorders: Issues for Consideration andPractice.Community Mental Health Journal, Vol. 27, No.4.

[12] Reichman, N.E., Corman, H. and Noonan K. (2008). Impact of Child Disability on the Family: Maternal and Child Health Journal.Medscape Publishers' Circle. ISSN: 1092-7875,1573-6628)

[13] Rozenweig, J.M. \& Huffstutter, K. (2003).Integrating employment with parenting of children having mental challenges, a paper presented at annual meeting of the Western Psychology Association, Vancouver: Canada.

[14] Sajjad, S. (2010).Stress Faced by Mothers of Children with Intellectual Disability and its Impact on their Family Life. University of Karachi: Pakistan.

[15] Schardein, J. (2000) Chemically Induced Birth Defects, 3rd ed. New York, Marcel Dekker. https://doi.org/10.3109/9780203909904.

[16] Scott, E. (2007). Mother Friends: How Mothers Can Use Friends To Relieve Stress. Retrieved from About.com Guide. Accessed on 23/03/ 2017.

[17] Uchino,B.N., Cacioppo, J.T., \&Kiecolt-Glaser, J.K. (1996).The Relationship between Social Support and Physiological Processes: A Review with Emphasis on Underlying Mechanisms and Implications for health: Psychological Bulletin, Volume 119 No.3. https://doi.org/10.1037/0033-2909.119.3.488.

[18] UNICEFF. (2013). The State of the World's Children 2013: Children with Disabilities. New York: Prographics, Inc. 